\title{
Graphene a Fundamental of Interaction Globe
}

\author{
R.Velvizhi, R.Kavitha, C. Geetha, S.R. Sri Vidhya
}

\begin{abstract}
Communication became certainly one of the integral parts into the social and development that is technical of beings. $B$ ut, the downside that is biggest within the contemporary realm of interaction is that the quantity of people utilizing mobile, internet as well as other such interaction surroundings are increasing at a significant price. This contributes to greater bandwidth requirement and much more than that, greater rate of information transfer. Because, as the amount of users enhance, greater would be the strain o letter various products which form the infrastructure that is fundamental of interaction globe.Graphene, a product found by Nobel Prize champions Andre Geim and Konstantin Novoselov is a product which assists in working with these specific things. It's a two type that is dimensional of which includes unique properties which will help in increasing the $d$ ata prices tremendously. The most crucial home of Graphene is the fact that sign moving through the products $c$ an flow with speeds reater that is $g$ the rate of light. One other properties[1] are its interestingly great energy and freedom that is superb. The products such as for example a ntennas, transistors, etc. developed by utilizing Graphene as the fundamental product $g$ ive better and gratification that is efficient. A great many other products like batteries and touch screens are more versatile and efficient whenever developed by utilizing Graphene.
\end{abstract}

Keyword phrases: Graphene, Scotch Tape Method, Graphenna, selective emission, coronene, nano-patch, superbattery.

\section{INTRODUCTION}

Graphene is simply a layer that is slim of carbon, the width of that is 1 atom dense. Generally in most situations, because the depth of this product decreases its conductivity decreases. But, in case there is graphene, it's many different.

Revised Manuscript Received on July 22, 2019.

R. Velvizhi, Department of CSE, Bharath Institute of Higher Education and Research,Chennai, Tamilnadu, India.

R. Kavitha, Department of CSE, Bharath Institute of Higher Education and Research,Chennai, Tamilnadu, India.

C. Geetha, Department of CSE, Bharath Institute of Higher Education and Research,Chennai, Tamilnadu, India.

S.R. Sri Vidhya, Department of CSE, Bharath Institute of Higher Education and Research,Chennai, Tamilnadu, India.
Graphene is a 2D layer of carbon atoms, has a lattice that is honeycomb as shown in fig. 1. It will have the conductivity that is minimum of all of the. But, in fact graphene gets the most widely known electrical and properties which can be technical.

A graphene sheet isn't completely flat, however it has corrugations which vibrate as graphene warms up. Graphene has high flexibility that is intrinsic that makes it well suited to utilizing it in gadgets, particularly MOSFETs.[2] Tall flexibility of electrons means graphene could also be used within the terahertz array of the range that is electromagnetic. It's around 100 times more powerful than metal and has now a conductivity that will be a lot better than copper in Fig:1.

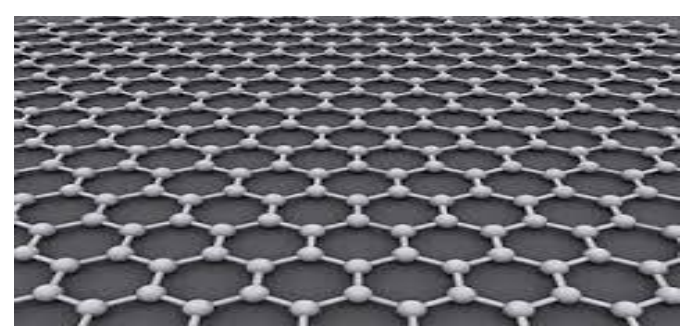

Figure1: Honeycomb lattice framework of graphene

Graphenec an be obtained in tiny amounts for experimental usage through the use of $t$ he famous "Scotch Tape Method" which ended up being utilized by Nobel Prize champions Andre Geim and Konstantin Novoselov, from Manchester University, U K. In this technique, the tape that is adhesive utilized to draw out graphene through the typical product kn very own as graphite o $\mathrm{r}$ lead. P lacing the tape on a lump of graphite after which eliminating it, they were able to tear down little chunks of graphite consisting of a layers being few. But, they got a tiny amount of graphite that was just two to three levels of atoms dense and periodically 1 atom layer dense because they repeated the method many times.[1, 2, 3]

The Graphene Antenna, also called Graphenna, is a proposed radio antenna which could offer a speed all the way to 100 terabits per second. The theory that is fundamental to produce an antenna that will be shaped into graphene strips from 10 to

100 letter anometers wide and one micrometer very long. These antennas would offer a rate about as high as 1 terabit per second well away of just one meter, 100 terabits per second up to a distance of just one $\mathrm{cm}$. Thus, these antennas will soon be utilising the range that is terahertz of. $[4,5,6]$. 


\section{FEATURES OF GRAPHENE}

i. Graphene has flexibility that is high all the way to 2 hundred times compared to s ilicon.

ii. It has extremely good thermal conductivity, that allows heat dissipation at a really rate that is quick.

iii. Mechanically additionallygraphene has discovered numerousadmirers. It's not just the thinnest of all of the (in other words. about one atom dense), but additionally the s trongest one.

iv. The resistivity made available from graphene is extremely lowassociated with order of $10^{-6} \Omega \cdot \mathrm{cm}$ that also offerimpetus towards the movement of electrons.[4]

v. This has transparency that is optical assists it to locate its applications in optical industry.

vi. Whenever exposed to illumination it creates large amount of electrons in comparison with silicon, makes it possible for the use that is maximum of of this photon as well as decreases heat dissipation.

vii. It really is atom thick sheet that is planar of atoms that also helps it be miniscule in proportions.

\section{FEATURES OF GRAPHENE WHEN APPLIED AS AN ANTENNA}

Scientists find brand new applications of graphene with every moving day. Each and every day that is alternative encounter brand new and interesting details about grapheme $[7,8,9]$. I ts applications are tremendous from the comfort of its use in car companies due to is power that is technical to IC companies because of fabulous conductivity, to your telecommunication industry and so many more.a group led by Akyildiz manager of broadband wireless cordless networking laboratory have actually discovered that graphene whenever utilized in making antennas has $\mathrm{m}$ any benefits $[10,11,12]$.

Firstly the biggest of them all is that it can increase information which are cordless price as much as terabits simply speaking range [13, 14, 15]. Akyildiz and his team have determined that at also faster ranges, such as for example a centimeters being few information prices as high as 100 terabits per second are theoretically feasible, as well as a distance of approximately one meter the transfer price can about one terabits per second. Cordless interaction with such a bandwidth that is gigantic solve the issue of information trafficking and time for which us er had to hold back. Involved in terabit price can move the info within almost no time [16, 17]. Graphene not just assists in $i$ ncreasing the transfer price but additionally assists in miniaturization of antennas. Graphene[5] made antennas will be much smaller that steel made antennas. Also Akyildiz and their group will work on graphene antenna that has proportions in nanometer which further will act as a catalyst for transfer price $[18,19]$

Tall flexibility of electrons in graphene helps it be ideal for ultra regularity that is high. At terahertz reconfiguration that is efficient feasible and also this additionally permits so named plasma sonic propagation. Graphene made antennas will even have energy that is technical freedom since well as durability. With so benefits that are many as well as additional in the future our methodgraphene made antenna can strike communication market with bang within several years [20, 21].

\section{SELECTIVE EMISSION}

Selective emission is a house unique to the graphene. The entire process of selective emission works the following. At first a Graphene based antenna is very carefully created according to requirements. Then, the particles are positioned into the specific area referred to as 'feed' of this antenna. Here is the area which takes rays that is electromagnetic offers it or feeds it towards the remaining portion of the antenna system. The entire process of putting the particles can be carried out by an force microscope that is atomic. It can be achieved by a microfluidic [22] hannel that is c. Then, a transfer of the molecule happens to an state that is exited. This is accomplished by a photon consumption technique into the visible or vary that is ultraviolet of.

Then, the antenna is tuned to your resonance regularity of this molecule. This is accomplished by triggering the gate gate voltage that is utilizing. The tuning is fairly just like the tuning of a radio. Coronene is a material extensively useful for synthesis of graphene, additionally utilized in systems where in fact the emission that is selective of graphene has been concentrated upon $[23,24]$.Coronene now loses power quite easily through the change of particles. Some other change just isn't impacted at a scale that is big. $\mathrm{T}$ he radiation prices of Coronene modification a ndit's called Purcell impact. Now, as you can find various states of coronene within the antenna,internal redistributions just take place between those states that are extremely fast. $\mathrm{M}$ uchmore fast compared to the radiation leisure prices of the continuing states on their own. Right here, as a result of this interior redistribution, then your molecule that was entered into the antenna will begin emitting light at that regularity to that your graphene antenna is tuned if one particular s tates loses power faster than other state $[25,26]$ This method is recognized as selective emission.

The particles which emit 1 ight aren't within the regularity domain that is optical. They have been in s o called THz-gap. Right here, numerous products which can be practical highly required. Now, at change frequencies, any antenna which can be metallic highly impact theradiation prices. Additionally, these noticeable metallic structures aren't tunable to a lot of frequencies and therefore it generates $t$ hem usable just at a change regularity that is solitary.[27, 28]

\section{EXPERIMENT ON NANO-PATCH ANTENNA}

In a test, scientists are suffering from a graphenebased nano-patch antenna for radiation in terahertz $r$ ange. They will have essentially 
analyzed the scattering of terahertz radiation of a graphene based nano-patch antenna numerically [29, 30]. They've numerically demonstrated the effectiveness of tunability for the antenna resonances via electrostatic bias, starting views to develop graphene that is tunablenano-patch antennas. These antennas are developed to essentially be utilized in nano-scale. Within the test they utilized the home of conductivity of graphene and in addition its scattering properties to build up numerical and analysis that is practical of antenna. They essentially analyzed rays and scattering $\mathrm{p}$ atterns of a rectangular nano-patch antenna that is graphene-based. The antenna into consideration is shown in fig. 2.

This test ended up being carried out by IgnacioLlaster, CristianKremers, Albert Cabellos-Aparicio, JosepMiquelJornet, Eduard Alarcon and Dmitri N. Chingrin. Every one of these scientists come from various universities from Europe and United States [31].

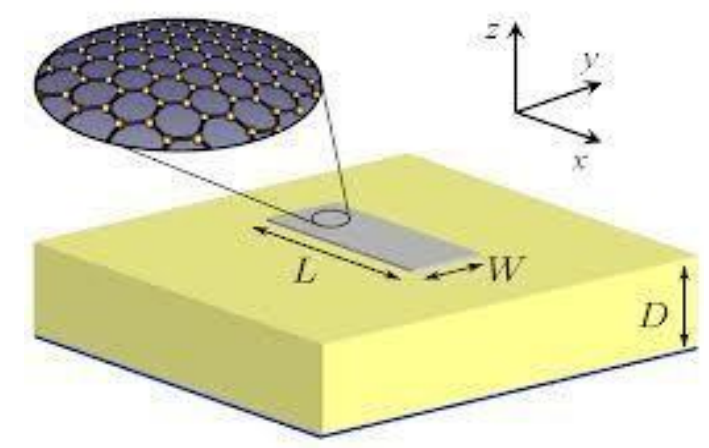

Figure 2: fundamental design associated with the Graphene Antenna into consideration

\section{FUTURE DEVELOPMENTS IN GRAPHENE}

We understand that o ne regarding the properties of graphene is it's an exceptionally good conductor of electricity which assists in changing extensively utilized material like "Silicon" or "Metals" in industry of electronic devices, allowing huge improvements in rate and effectiveness ergo professional information that is vidingo $f$ about 100 terabits per second, which can be adequate in moving the articles of a ordinary hard disk drive in only a couple of seconds.[32].

Graphene as world's most useful battery pack that is super designers have found ways to keep electric fees in graphene ultra that is antenna-based devices. There are two main methods of achieving this. Firstly, utilizing oldfashioned batteries which can be rechargeable secondly us age of ultra capacitors, that is much more safer, cooler and operates much longer [33]. This can not just be beneficial in solar and power that is wind $b$ ut will also enhance effectiveness of electric devices, vehicles, trains, etc.

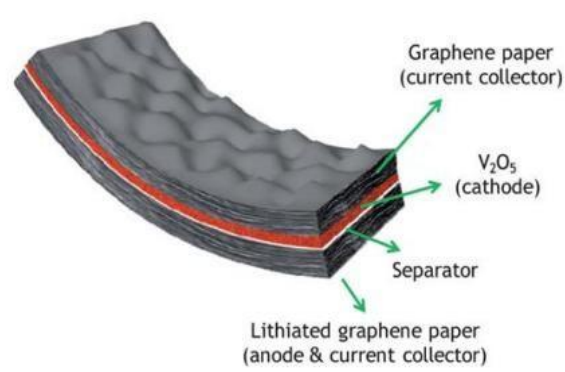

Bendable resilient and battery pack that is versatilePhones and pills have actually changed the application of publications and mags in every feeling aside from one ie. hi-tech gizmos can't be bent on our whim, however now they may be by utilization of graphene. $\mathrm{T}$ he lithium-ion battery pack could be flex over backwards without causing any deflections in the energy. This is e xtremely beneficial in versatile e-reader and $\mathrm{f}$ e-phones which are lexible [34].

Touch-screens usage graphene:

Touchscreen display can be built away from graphene. Right here, graphene can be utilized as a element that is conductive. It can be printed in a plastic that is slim rather than utilizing a glass sheet. This might result in the displays and also the phones too, extremely versatile and light. A nd flexibility, these cellular phones is slim, tough and almost unbreakable as a result of graphene's energy.[35].

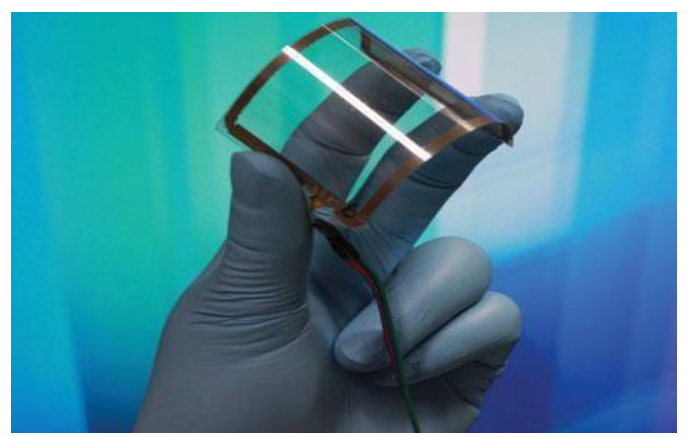

Figure 4: A researcher showing the touch-screen that is bendable using Graphene

Graphene transistors give bioelectronics a good start:The peoples stressed system was a letter inspiration for designers to create Graphene-based transistors to react to the alterations in the chemical framework that is interior. Procedures like retinal implants are easy for aesthetically reduced individuals. The investigation centerso letter the voltage that is little a neuron produces throughout the mobile membrane layer. Now, the distinction that is possible hich arises through the salt ions additionally the potassium ions could be the the one which creates the voltage within the letter euron $[36,37]$.

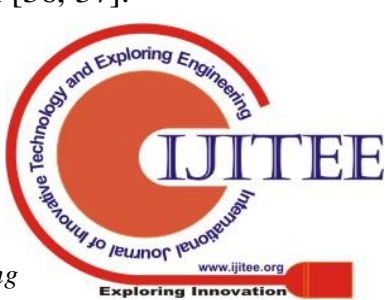


Nobody has really built an antenna and there is a large number of obstacles what type has to tackle even though this appears excellent the theory is that. First of all, Graphene i n it self is extremelyhard to make, and far regarding the infrastructure that is current to $b$ e entirely redesigned around it. But, since s o numerous applications which are brand new being lofted that all the young and enthusiastic clinical minds are desperate to find solutions $[38,39]$.

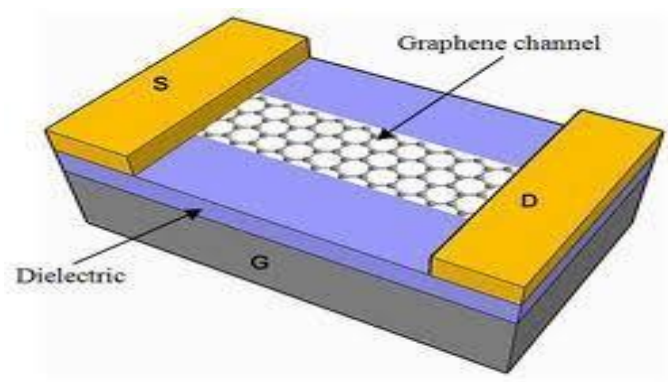

Figure 5: Graphene based MOSFET

Graphene based Schottkey-Junction Solar Panels

The Schottky $\mathrm{j}$ unction has product universality, it has cost that is low is simple to fabricate. Thus it really is a alternative that is great solar mobile framework. But, graphene based solar cells have actually the main advantage of reduced expenses, security that is better and a great deal of freedom. These facets are missing in old-fashioned indium-tin-oxide (ITO) based junction that isschottky cells $[40,41]$.

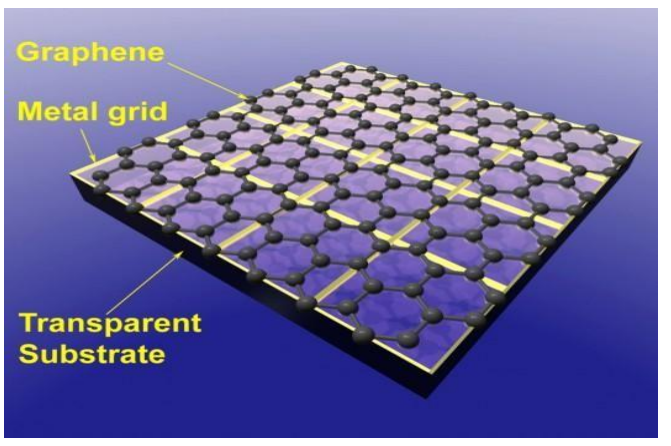

Figure 6. S panels which are olarGraphene

\section{CONCLUSION}

The paper product reviews the creating of graphene, its different technical benefits and its particular uses into the different channels of this globe that is technical. It primarily concentrates o letter grapheneas a variety that is brief and in addition emphasizes regarding the selective age objective home of graphene which allows that it is found in different interaction applications. The properties of graphene which find applications in several industries are discussed briefly. The f uture range of grapheneh as been discussed into the paper.

\section{REFERENCES}

[1] Kumarave A., RangarajanK.,Algorithm for automaton specification for exploring dynamic labyrinths, Indian Journal of Science and Technology,V-6,I-SUPPL5,PP-4554-4559,Y-2013

[2] P. Kavitha, S. Prabakaran "A Novel Hybrid Segmentation Method with Particle Swarm Optimization and Fuzzy C-Mean Based On Partitioning the Image for Detecting Lung Cancer" International Journal of Engineering and Advanced Technology (IJEAT) ISSN: 2249-8958, Volume-8 Issue-5, June 2019

[3] Kumaravel A., MeeteiO.N.,An application of non-uniform cellular automata for efficient cryptography,2013 IEEE Conference on Information and Communication Technologies, ICT 2013,V-,I,PP-1200-1205,Y-2013

[4] Kumarave A., RangarajanK.,Routingalogrithm over semi-regular tessellations,2013 IEEE Conference on Information and Communication Technologies, ICT 2013,V-,I-,PP-1180-1184,Y2013

[5] P. Kavitha, S. Prabakaran "Designing a Feature Vector for Statistical Texture Analysis of Brain Tumor" International Journal of Engineering and Advanced Technology (IJEAT) ISSN: 2249-8958, Volume-8 Issue-5, June 2019

[6] Dutta P., Kumaravel A.,A novel approach to trust based identification of leaders in social networks, Indian Journal of Science and Technology,V-9,I-10,PP--,Y-2016

[7] Kumaravel A., DuttaP.,Application of Pca for context selection for collaborative filtering,Middle - East Journal of Scientific Research,V-20,I-1,PP-88-93,Y-2014

[8] Kumaravel A., RangarajanK.,Constructing an automaton for exploring dynamic labyrinths,2012 International Conference on Radar, Communication and Computing, ICRCC 2012,V-,I-,PP$161-165, Y-2012$

[9] P. Kavitha, S. Prabakaran "Adaptive Bilateral Filter for MultiResolution in Brain Tumor Recognition" International Journal of Innovative Technology and Exploring Engineering (IJITEE) ISSN: 2278-3075, Volume-8 Issue-8 June, 2019

[10] KumaravelA.,Comparison of two multi-classification approaches for detecting network attacks, World Applied Sciences Journal,V27,I-11,PP-1461-1465,Y-2013

[11] Tariq J., KumaravelA.,Construction of cellular automata over hexagonal and triangular tessellations for path planning of multirobots,2016 IEEE International Conference on Computational Intelligence and Computing Research, ICCIC 2016,V-,I-,PP--,Y2017

[12] Sudha M., KumaravelA.,Analysis and measurement of wave guides using poissonmethod,Indonesian Journal of Electrical Engineering and Computer Science, V-8,I-2,PP-546-548,Y-2017

[13] Ayyappan G., Nalini C., KumaravelA.,Various approaches of knowledge transfer in academic social network,International Journal of Engineering and Technology,V-,I-,PP-2791-2794,Y2017

[14] Kaliyamurthie, K.P., Sivaraman, K., Ramesh, S. Imposing patient data privacy in wireless medical sensor networks through homomorphic cryptosystems 2016, Journal of Chemical and Pharmaceutical Sciences $\quad 9 \quad 2$.

[15] Kaliyamurthie, K.P., Balasubramanian, P.C. An approach to multi secure to historical malformed documents using integer ripple transfiguration 2016 Journal of Chemical and Pharmaceutical Sciences9

2. extractions in the web", International Journal of Engineering \& Technology, 7 (2.6) (2018) 290-292

[17] S.V.GayathiriDevi,C.Nalini,N.Kumar,"An efficient software verification using multi-layered software verification tool "International Journal of Engineering \& Technology, 7(2.21)2018 454-457

[18] C.Nalini,ShwtambariKharabe,"A Comparative Study On Different Techniques Used For Finger - Vein Authentication", International Journal Of 
Pure And Applied Mathematics, Volume 116 No. 8 2017, 327 333, Issn: 1314-3395

[19] M.S. Vivekanandan and Dr. C. Rajabhushanam, "Enabling Privacy Protection and Content Assurance in Geo-Social Networks", International Journal of Innovative Research in Management, Engineering and Technology, Vol 3, Issue 4, pp. 49-55, April 2018.

[20] Dr. C. Rajabhushanam, V. Karthik, and G. Vivek, "Elasticity in Cloud Computing", International Journal of Innovative Research in Management, Engineering and Technology, Vol 3, Issue 4, pp. 104-111, April 2018.

[21] K. Rangaswamy and Dr. C. Rajabhushanamc, "CCN-Based Congestion Control Mechanism In Dynamic Networks", International Journal of Innovative Research in Management, Engineering and Technology, Vol 3, Issue 4, pp. 117-119, April 2018.

[22] Kavitha, R., Nedunchelian, R., "Domain-specific Search engine optimization using healthcare ontology and a neural network backpropagation approach", 2017, Research Journal of Biotechnology, Special Issue 2:157-166

[23] Kavitha, G., Kavitha, R., "An analysis to improve throughput of high-power hubs in mobile ad hoc network", 2016, Journal of Chemical and Pharmaceutical Sciences, Vol-9, Issue-2: 361-363

[24] Kavitha, G., Kavitha, R., "Dipping interference to supplement throughput in MANET" , 2016, Journal of Chemical and Pharmaceutical Sciences, Vol-9, Issue-2: 357-360

[25] Michael, G., Chandrasekar, A.,"Leader election based malicious detection and response system in MANET using mechanism design approach", Journal of Chemical and Pharmaceutical Sciences(JCPS) Volume 9 Issue 2, April - June 2016.

[26] Michael, G., Chandrasekar, A.,"Modeling of detection of camouflaging worm using epidemic dynamic model and power spectral density", Journal of Chemical and Pharmaceutical Sciences(JCPS) Volume 9 Issue 2, April - June 2016.

[27] Pothumani, S., Sriram, M., Sridhar, J., Arul Selvan, G., Secure mobile agents communication on intranet,Journal of Chemical and Pharmaceutical Sciences, volume 9, Issue 3, Pg No S32-S35, 2016

[28] Pothumani, S., Sriram, M., Sridhar, Various schemes for database encryption-a survey, Journal of Chemical and Pharmaceutical Sciences, volume 9, Issue 3, Pg NoS103-S106, 2016

[29] Pothumani, S., Sriram, M., Sridhar, A novel economic framework for cloud and grid computing, Journal of Chemical and Pharmaceutical Sciences, volume 9, Issue 3, Pg No S29-S31, 2016

[30] Priya, N., Sridhar, J., Sriram, M. "Ecommerce Transaction Security Challenges and Prevention Methods- New Approach" 2016 ,Journal of Chemical and Pharmaceutical Sciences, JCPS Volume 9 Issue 3.page no:S66-S68 .

[31] Priya, N.,Sridhar,J.,Sriram, M."Vehicular cloud computing security issues and solutions" Journal of Chemical and Pharmaceutical Sciences(JCPS) Volume 9 Issue 2, April - June 2016

[32] Priya, N., Sridhar, J., Sriram, M. "Mobile large data storage security in cloud computing environment-a new approach" JCPS Volume 9 Issue 2. April - June 2016

[33] Anuradha.C, Khanna.V, "Improving network performance and security in WSN using decentralized hypothesis testing "Journal of Chemical and Pharmaceutical Sciences(JCPS) Volume 9 Issue 2, April - June 2016.

[34] Anuradha.C, Khanna.V, "A novel gsm based control for edevices" Journal of Chemical and Pharmaceutical Sciences(JCPS) Volume 9 Issue 2, April - June 2016

[35] Anuradha.C, Khanna.V, "Secured privacy preserving sharing and data integration in mobile web environments " Journal of Chemical and Pharmaceutical Sciences(JCPS) Volume 9 Issue 2, April - June 2016 .

[36] Sundarraj, B., Kaliyamurthie, K.P. Social network analysis for decisive the ultimate classification from the ensemble to boost accuracy rates 2016 International Journal of Pharmacy and Technology 8

[37] Sundarraj, B., Kaliyamurthie, K.P. A content-based spam filtering approach victimisation artificial neural networks 2016

International Journal of Pharmacy and Technology 83.
[38] Sundarraj, B., Kaliyamurthie, K.P. Remote sensing imaging for satellite image segmentation $2016 \quad$ International Journal of Pharmacy and Technology $\quad 8 \quad 3$.

[39] Sivaraman, K., Senthil, M. Intuitive driver proxy control using artificial intelligence 2016 International Journal of Pharmacy and Technology $\quad 8 \quad 4$.

[40] Sivaraman, K., Kaliyamurthie, K.P. Cloud computing in mobile technology $2016 \quad$ Journal of Chemical and Pharmaceutical Sciences 92 .

[41] Sivaraman, K., Khanna, V. Implementation of an extension for browser to detect vulnerable elements on web pages and avoid click jacking 2016 Journal of Chemical and Pharmaceutical Sciences9 2 .

\section{AUTHORS PROFILE}

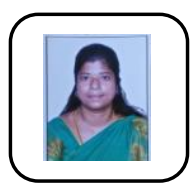

R. Velvizhi, Assistant Professor, Department of Computer Science \& Engineering, Bharath Institute of Higher Education and Research,Chennai, India

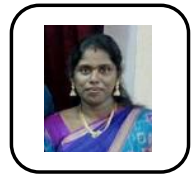

R. Kavitha, Assistant Professor, Department of Computer Science \& Engineering, Bharath Institute of Higher Education and Research,Chennai, India

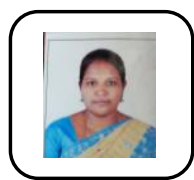

C. Geetha, Assistant Professor, Department of Computer Science \& Engineering, Bharath Institute of Higher Education and Research,Chennai, India

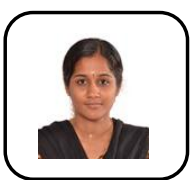

S.R. Sri Vidhya, Assistant Professor, Department of Computer Science \& Engineering, Bharath Institute of Higher Education and Research,Chennai, India 